\title{
Sífilis congénita tardía: a propósito de un caso
}

Late congenital syphilis: case report

\author{
Dr. Martín A. Amaya ${ }^{a}$, Dra. Griselda Berberian ${ }^{b}$, Bioq. Ana Buchovskyc, Bioq. Marina Costa ${ }^{c} y$ \\ Dra. Mariana Nastri ${ }^{d}$
}

\section{RESUMEN}

La sífilis presenta un marcado aumento de su prevalencia en Argentina y en el mundo. La Organización Mundial de la Salud estima que, por año, hay 12 millones de personas infectadas mundialmente, y 270000 corresponden a recién nacidos con sífilis congénita.

Se presenta a una niña de 8 años de edad con mononucleosis por virus de Epstein-Barr, que mostró como hallazgo diagnóstico sífilis confirmada por dos pruebas treponémicas positivas; se interpretó el cuadro como compatible con sífilis congénita latente tardía asintomática.

Palabras clave: Treponema pallidum, sífilis congénita, algoritmos/ serología, tratamiento, abuso sexual infantil.

\begin{abstract}
Syphilis shows marked increase in its prevalence in Argentina and the world. The World Health Organization estimates that annually there are 12 million people infected in the world, 270,000 corresponding to newborns with congenital syphilis. We describe an 8-year-old girl who was undergoing mononucleosis due to Epstein-Barr virus and presented syphilis as a diagnostic finding, confirmed by two different positive treponemal tests, assuming a compatible picture of late latent congenital asymptomatic syphilis.

Key words: Treponema pallidum, congenital syphilis, serology/ algorithms, treatment, child sexual abuse.
\end{abstract}

http: / / dx.doi.org/10.5546/ aap.2019.e399

Cómo citar: Amaya MA, Berberian G, Buchovsky A, Costa M, Nastri M. Sífilis congénita tardía: a propósito de un caso. Arch Argent Pediatr 2019;117(4):e399-e402.

a. Clínica Pediátrica, Medicina Interna, "Hospital de Pediatría Prof. Dr. Juan P. Garrahan", Ciudad Autónoma de Buenos Aires.

b. Servicio de Epidemiología e Infectología, "Hospital de Pediatría Prof. Dr. Juan P. Garrahan”, Ciudad Autónoma de Buenos Aires.

c. Laboratorio de Serología, "Hospital de Pediatría Prof. Dr. Juan P. Garrahan", Ciudad Autónoma de Buenos Aires.

d. Sector de Bajo Riesgo, Servicio de Clínica, "Hospital de Pediatría Prof. Dr. Juan P. Garrahan", Ciudad Autónoma de Buenos Aires.

Correspondencia:

Dr. Martín A. Amaya: martin-amaya@hotmail.com

Financiamiento: Ninguno.

Conflicto de intereses: Ninguno que declarar.

\section{INTRODUCCIÓN}

La sífilis presenta un marcado aumento de su prevalencia en Argentina y en el mundo. La Organización Mundial de la Salud (OMS) estima que, por año, hay 12 millones de personas infectadas mundialmente, y 270000 corresponden a recién nacidos $(\mathrm{RN})$ con sífilis congénita. ${ }^{1,2}$

En 2016, en Argentina, se notificaron 545 casos totales y 212 confirmados de sífilis congénita. Correspondieron, en su gran mayoría, a la zona Centro del país (Ciudad Autónoma de Buenos Aires-CABA-, Buenos Aires, Córdoba, Entre Ríos y Santa Fe). ${ }^{3}$

Según informes del Ministerio de Salud de la Nación (MSAL), entre 2011 y 2017, pasaron de 3875 casos reportados a 11709 , sin considerarse los casos no notificados o no diagnosticados, ya sea por la falta de consulta por parte de la población o por la falta de sospecha y confirmación diagnóstica. Este aumento de incidencia se describe en adolescentes y en adultos, sin modificaciones por clase social, según el Boletín Integrado de Vigilancia Epidemiológica del MSAL. $^{3}$

La transmisión vertical del Treponema pallidum (TP) se produce, principalmente, por vía transplacentaria y, rara vez, por contagio en el canal de parto; es mayor el riesgo de transmisión en el caso de infección materna reciente y a mayor edad gestacional. ${ }^{4}$

Una forma inusual de presentación de la sífilis congénita es la infección latente asintomática, con síntomas, o bien con secuelas tardías.

La sífilis congénita tardía se presenta en los niños mayores de dos años y puede evidenciarse entre los cinco y los catorce años. ${ }^{5}$ Puede ser asintomática y detectarse a partir de sus complicaciones tardías. ${ }^{6}$

Las pruebas serológicas representan el método de elección para el diagnóstico, el estudio familiar y el seguimiento.

Se presenta a una niña de 8 años con diagnóstico de sífilis congénita tardía asintomática. 


\section{CASO CLÍNICO}

Paciente de 8 años de edad que presentó fiebre y odinofagia, adenomegalias laterocervicales bilaterales inflamatorias y faringitis eritematosa. Se le realizó el cultivo del hisopado de fauces, que fue negativo. Evolucionó con astenia, artralgias y persistencia de la fiebre, por lo que se solicitaron otros exámenes complementarios.

Se constataron leucocitosis, elevación de transaminasas (transaminasa glutámicooxalacética -glutamic oxaloacetic transaminase; GOT, por sus siglas en inglés-: $111 \mathrm{UI} / 1$; transaminasa glutámico-pirúvica-glutamicpyruvic transaminase; GPT, por sus siglas en inglés-: $232 \mathrm{UI} / 1$; valores de bilirrubina total y fosfatasa alcalina -FAL- normales) y proteína $\mathrm{C}$ reactiva (PCR): 17,27 mg/l. Serologías: virus de la inmunodeficiencia humana (VIH) negativo, virus de la hepatitis $C$ (hepatitis $C$ virus; $H C V$, por sus siglas en inglés) negativo, Epstein-Barr virus $(E B V)$ inmunoglobulina $\mathrm{M}(\operatorname{Ig} \mathrm{M})$ positivo, inmunoglobulina $\mathrm{G}(\mathrm{IgG})$ positivo, EBV nuclear antigen (EBNA) negativo, citomegalovirus IgM positivo, IgG positivo, virus de la hepatitis $B$ (hepatitis $B$ virus; $H B V$ por sus siglas en inglés) negativo y pruebas treponémicas (PT) y prueba serológica para la sífilis (venereal disease research laboratory test; $V D R L$, por sus siglas en inglés) positivas.

Los resultados serológicos positivos para infección aguda por $E B V$ con la IgM anticápside y early antigen ( $E A$ ) positiva fueron confirmados con la seroconversión posterior con EBNA IgG positivo. La serología IgM para citomegalovirus positivo se interpretó como una probable reacción cruzada por la persistencia de títulos de citomegalovirus IgG estables.

La prueba treponémica (anti-TP, método chemiluminescent microparticle immunoassay CMIA-) fue positiva (relación de positividad Sample/Cut off $-S / C O-=16,58)$ y la prueba no treponémica $(V D R L)$ fue reactiva de 1 dils.

Durante la tercera consulta, la madre refirió que la niña había nacido de la primera gesta de un embarazo controlado, con serologías negativas. Luego de dos años, durante un estudio preocupacional de la madre, se informó serología positiva para sífilis, por lo que ella y su pareja realizaron el tratamiento con penicilina, y no se estudió a la niña en dicha oportunidad. La madre no recordaba lesiones ni exantemas y refirió que la niña había recibido, en múltiples oportunidades, amoxicilina, azitromicina y penicilina por infecciones de la vía aérea superior.
Se reinterrogó a la familia para descartar abuso sexual infantil (ASI); se interconsultó con Infectología y se planteó el caso como sífilis. Se debía descartar la forma de adquisición congénita tardía o adquirida, motivo por el cual se realizaron estudios serológicos a los convivientes. La madre: anti-TP CMIA positiva con VDRL no reactiva (patrón de sífilis tratada); la hermana y la pareja conviviente: negativas; no se logró realizar estudios serológicos al padre biológico, quien refirió haber realizado el tratamiento al mismo tiempo que la madre de la niña. En forma simultánea, se inició el seguimiento por Servicio Social.

Se repitió la prueba treponémica a la niña, que fue positiva, y se confirmó con una segunda prueba treponémica (fluorescent treponemal antibody absorption, FTA-abs), que también se envió al centro de referencia.

La evaluación ginecológica fue normal; el fondo de ojos, las radiografías de cráneo, de tórax y de huesos largos fueron normales, y se decidió su internación para continuar los estudios y el tratamiento. Durante esta, se realizó la evaluación auditiva, que fue normal, una punción lumbar con $V D R L$, negativa, el citoquímico, normal, y la evaluación interdisciplinaria para descartar ASI, de la cual no sumó criterios clínicos, familiares ni psicopatológicos. Cumplió diez días de tratamiento con penicilina endovenosa. Egresó manteniendo el seguimiento ambulatorio.

\section{DISCUSIÓN}

En la edad pediátrica, la sífilis con relación al momento de adquisición puede ser congénita o adquirida. La sífilis adquirida se debe, en su mayoría, a la transmisión sexual, por lo que resulta importante su diferenciación para el diagnóstico, el tratamiento y la prevención. ${ }^{7}$

Debe considerarse dentro de las causas de ASI, definido como el compromiso de un niño en actividades sexuales que no corresponden a su etapa evolutiva, emocionalmente inmaduro y dependiente, que no está capacitado para dar su consentimiento a acciones que violan los tabúes de los roles familiares y de la cultura a la que pertenecen. Son factores de riesgo niñas, menores de cinco años, personalidades introvertidas, discapacidad, desamparo afectivo y factores socioeconómicos. ${ }^{8}$

La sospecha del pediatra a partir de la anamnesis, signos o síntomas orientadores (actitud durante la consulta, lesiones genitales o anales, juegos sexuales inapropiados para la 
edad, trastornos del sueño, miedos intensos, enuresis o encopresis secundaria, crisis de llanto sin explicación, cambios en las conductas alimentarias y laboratorio orientador) es de gran importancia. ${ }^{8}$

Las manifestaciones clínicas de la sífilis congénita pueden ser precoces o tardías de acuerdo con el momento de presentación dividido antes o después de los 2 años de vida. Entre las complicaciones tardías, están la sordera neurosensorial, la queratitis intersticial, periostitis, huesos frontales prominentes, depresión del puente nasal, deformidad con curvatura anterior de las tibias (tibias en sable), artritis tardía de las rodillas (articulaciones de Clutton), anomalías dentarias (dientes de Hutchinson). ${ }^{2-8}$

El paciente no tratado entra en una fase de latencia, en la que el diagnóstico solo puede hacerse mediante análisis serológicos. La sífilis latente es la fase durante la cual las pruebas serológicas son reactivas sin que se observen manifestaciones clínicas. ${ }^{9,10}$

El diagnóstico de laboratorio es serológico; se necesita de las pruebas no treponémicas (VDRL, rapid plasma reagin $-R P R-$, unheated serum reagin $-U S R-)$, que deben confirmarse con una prueba específica (ensayo de microhemaglutinación -microhemagglutination assay for Treponema pallidum antibodies; $M H A-T P$, por sus siglas en inglés-, FTA-abs, CMIA). Las primeras son muy sensibles, pero poco específicas, ${ }^{9}$ dado que

FIgURA 1. Algoritmo convencional para el diagnóstico serológico de sífilis

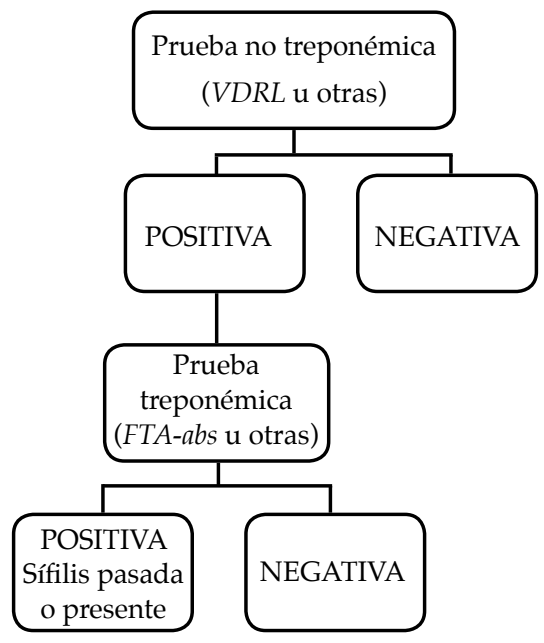

Fuente: elaborado por los autores.

$V D R L$ : prueba serológica para la sífilis;

FTA-abs: fluorescent treponemal antibody absorption. detectan anticuerpos contra antígenos lipoidales liberados de las células dañadas. Las pruebas no treponémicas son las únicas reacciones útiles para el seguimiento. La VDRL es la única prueba validada para ser utilizada en la muestra de líquido cefalorraquídeo. ${ }^{9}$ (Figuras 1 y 2 ).

En el Hospital, se utiliza el algoritmo reverso para el diagnóstico de sífilis desde 2014, lo que permite un screening rápido, con buena sensibilidad y especificidad, que evita la pérdida de casos debido a los falsos negativos de la VDRL y facilita, a través de un método automatizado, el diagnóstico de gran cantidad de muestras.

Los resultados falsos negativos pueden ocurrir con pruebas no treponémicas debido a un fenómeno conocido como reacción de prozona en el caso de alta cantidad de anticuerpos, o bien por el retraso habitual que se produce entre la infección y la positivización serológica, que puede ser de 2 meses. Debe tenerse en cuenta esta situación cuando la sospecha clínica de sífilis es alta y se obtienen resultados reactivos con títulos bajos o negativos. Esto no ocurre cuando el diagnóstico se hace por algoritmo reverso, en

FIgURA 2. Algoritmo reverso para el diagnóstico serológico de sifilis

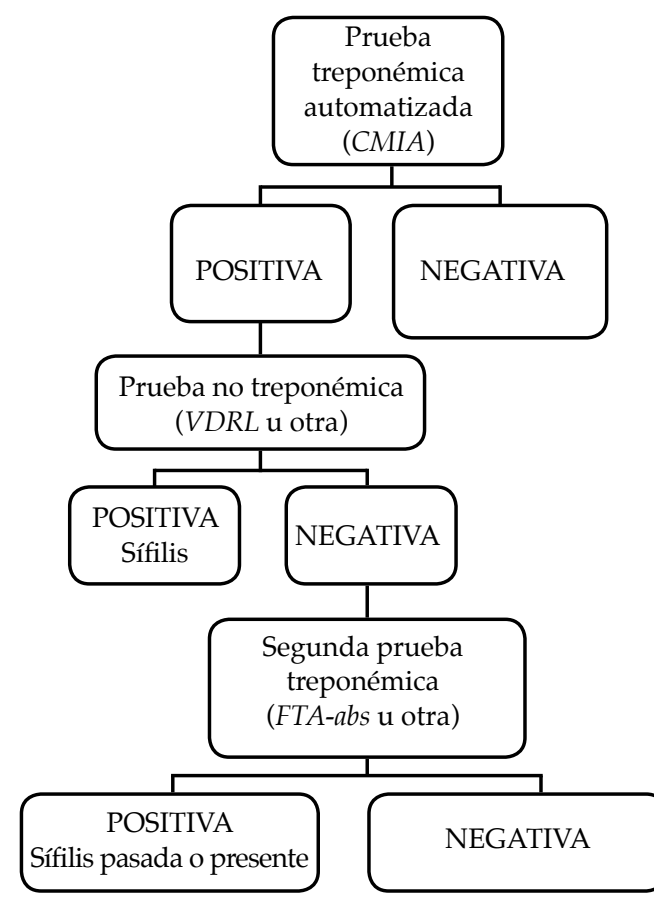

Fuente: elaborado por los autores.

CMIA: chemiluminescent microparticle immunoassay;

$V D R L$ : prueba serológica para la sífilis;

FTA: fluorescent treponemal antibody absorption. 
el cual la presencia de un resultado positivo con títulos representativos implicaría infección.

En la sífilis latente temprana, las pruebas no treponémicas son reactivas. Al aumentar el tiempo entre la infección inicial y las pruebas serológicas, disminuye la probabilidad de una prueba no treponémica reactiva. ${ }^{11}$

A pesar de que son menos sensibles que las pruebas treponémicas en la infección de larga duración, las pruebas no treponémicas se utilizan como prueba inicial porque es menos probable que sean reactivas después de la sífilis tratada con éxito y son fáciles de preformar.

En el caso presentado, la VDRL fue de 1 dils. y la prueba treponémica positiva, confirmada por 2 técnicas. Este análisis de laboratorio fue solicitado por el antecedente relatado por la madre, por lo que la serología referida como negativa durante el embarazo para sífilis podría corresponder a un falso negativo, o bien a un período de ventana entre la infección y la seroconversión.

El tratamiento de la sífilis varía según la forma de adquisición y la edad del paciente. La penicilina endovenosa de 10-14 días es el tratamiento de elección para la forma congénita.

Con el antecedente materno de la sífilis diagnosticada en el posparto, la ausencia de factores de riesgo de ASI, los títulos bajos de VDRL y la confirmación por 2 métodos treponémicos y la niña asintomática, el diagnóstico fue de sífilis congénita latente tardía.

La sífilis congénita es una enfermedad prevenible y tratable, que podría eliminarse mediante el control prenatal eficaz, el tratamiento de las embarazadas infectadas y sus parejas y de los casos de sífilis a cualquier edad, sumados a la educación sexual y a las medidas de prevención de las infecciones de transmisión sexual (ITS). ${ }^{2}$

\section{CONCLUSIÓN}

Teniendo en cuenta el aumento de la incidencia de sífilis y la forma variada y pleomorfa de presentación, el pediatra debe tenerla en cuenta para poder, así, diagnosticar y tratar dicha enfermedad.

\section{REFERENCIAS}

1. Cofre F, Delpiano L, Labrana Y, Reyes A, et al. Síndrome de TORCH: enfoque racional de diagnóstico y tratamiento pre-y posnatal. Recomendaciones delComité Consultivo de Infecciones Neonatales, Sociedad Chilena de Infectología, 2016. Rev Chil Infectol. 2016; 33(2):191-216.

2. Ministerio de Salud de la Nación. Organización Panamericana de la Salud. UNICEF. UNFPA. VIH y sífilis. Seroprevalencia en puérperas en Argentina. Diciembre 2012. [Acceso: 6 de junio 2018]. Disponible en: http:// www.msal.gob.ar/sida/images/stories/4-publicaciones / pdf/2013-09_VIH_Sifilis_Web.pdf.

3. Ministerio de Salud de la Nación. Sífilis congénita. Boletín Integrado de Vigilancia. 2017;356(SE16):81. [Acceso: 9 de junio de 2018]. Disponible en: http: / / www.msal.gob.ar/ images / stories / boletines / boletin_integrado_vigilancia_ N356-SE16.pdf.

4. Pérez Gutiérrez F. Sífilis congénita. Rev Méd Costa Rica. 1979; 46(467):87-91.

5. Comité Nacional de Infectología de la Sociedad Argentina de Pediatría. Treponema pallidum: sífilis. En: Libro azul de infectología Pediátrica. $4 .{ }^{\text {ta }}$ ed. Buenos Aires: FUNDASAP; 2012.Págs.671-6.

6. Larsen S, Johnson R. Diagnosis test. In Larsen S, Pope V, Jonshon R, Kennedy E (eds.). A manual of test for Syphilis. 9th ed. Washington DC: American Public Health Association, 1998.

7. Bologna R. Sífilis congénita: todavía con nosotros y en aumento. Rev Med infant. 2017; 24(4):361-3.

8. Comité de Salud Mental de la Sociedad argentina de Pediatría. Grupo de Trabajo sobre Violencia Familiar. Qué hacer cuando se sospecha que un niño es abusado sexualmente. Arch Argent Pediatr. 2007; 105(4):357-67.

9. Bruno M, Vulcano S, Gaiano A, Kaynar V, et al. Prevención de la transmisión perinatal de: Sífilis, Hepatitis B y VIH. Recomendaciones para el trabajo de los equipos de salud. Buenos Aires; Ministerio de Salud de la Nación. Dirección de SIDA y ETS; 2016. [Acceso: 8 de junio de 2018]. Disponible en: http: / / www.msal.gob.ar/images / stories / bes/graficos / 0000000853cnt-2016-07_guia-transmisionperinatal.pdf.

10._Workowski KA, Bolan GA.Sexually Transmitted Diseases. Treatment guidelines, 2015. MMWR Morb Mortal Wkly Rep. 2015; 64(RR3):1-137.

11. Soreng K, Lew R, Fakile Y. Serologic Testing for Syphilis: Benefits and Challenges of a Reverse Algorithm. Clin Microbiol Newsl. 2014; 36(24):195-202. 